\title{
Metal Ammine Formation in Solution. XVII. Stability Constants of Copper(II) Methylamine and Diethylamine Complexes Obtained from Solubility Measurements with Gerhardtite, $\mathrm{Cu}(\mathrm{OH})_{1.5}\left(\mathrm{NO}_{3}\right)_{0.5}$
}

\author{
LILIANA ILCHEVA* and JANNIK BJERRUM
}

Chemistry Department I, Inorganic Chemistry, H. C. Ørsted Institute, University of Copenhagen, DK-2100 Copenhagen $\varnothing$, Denmark

The solubility curve for the slightly soluble basic copper(II) nitrate gerhardtite $\left(\mathrm{Cu}(\mathrm{OH})_{1.5}\right.$ $\left.\left(\mathrm{NO}_{3}\right)_{0.5}\right)$ in $2 \mathrm{M}$ methylammonium nitrate and $2 \mathrm{M}$ diethylammonium nitrate, at $25^{\circ} \mathrm{C}$ and in the $\mathrm{pH}$ range 4 to 9 , has been determined by atomic absorption spectroscopy. From the data it was possible to estimate all of the consecutive stability constants in the methylamine-aqua system $\left(K_{1}=10^{4.11}, K_{2}=10^{3.40}\right.$, $K_{3}=10^{2.70}, K_{4}=10^{1.87}$ ) and the orders of magnitude of the first stability constants in the diethylamine system. The constants differ only slightly from those in the copper(II)-ammonia system. The ammine formation with the aliphatic amines is somewhat influenced by hydroxo complex formation, for which a correction was introduced.

The solubility product of gerhardtite $K_{\mathrm{s}}=$ $\left[\mathrm{Cu}^{2+}\right]\left[\mathrm{OH}^{-}\right]^{1.5}\left[\mathrm{NO}_{3}^{-}\right]^{0.5}$ and the saturation constant $s=\left[\mathrm{Cu}^{2+}\right][\mathrm{am}]^{1.5}$ were found to be $10^{-15.75}$ and $10^{-10.50}$, respectively, in $2 \mathrm{M}$ methylammonium nitrate and $10^{-16.12}$ and $10^{-11.35}$, respec. tively, in $2 \mathrm{M}$ diethylammonium nitrate.

Ammonia and aliphatic amines behave rather similarly in their complex formation with silver(I) and mercury(II) ions. ${ }^{1-3}$ The steric requirements of the amines thus appear to be only slightly greater than for ammonia, and it is of some interest to see to what extent this is the case for metal ions with a higher characteristic coordination number." For this purpose we have in the present work studied the complex formation of copper(II) ions with methylamine and diethylamine in $2 \mathrm{M}$ solu-

* On leave from Chemico-Technological Institute, Analytical Chemistry Department, Sofia 56, Bulgaria. tions of the corresponding alkylammonium nitrates. These particular amines are such strong bases that they almost completely precipitate the copper(II) ions in the $\mathrm{pH}$-range in which the ammine complexes are formed, even in the presence of high concentrations of the alkylammonium salts. The usual method of determining the stability constants, involv. ing the determination of the formation curve by means of pH-measurements, cannot therefore be used. One has to look for an alternative method, and one obvious possibility is to try to combine pH-measurements with solubility measurements on the basic precipitate formed. This method was found to work well in the present case where the precipitate is a basic copper(II) nitrate $\left(\mathrm{Cu}(\mathrm{OH})_{1.5}\left(\mathrm{NO}_{3}\right)_{0.5}\right)$ found in nature as "gerhardtite". It has been shown earlier ${ }^{5}$ by one of the present authors that gerhardtite has a well-defined solubility in ammonium nitrate solutions. Saturation is slow but equilibrium is reached after $1-2$ weeks.

\section{EXPERIMENTAL}

Chemicals. All reagents were of analytical grade or of good commercial quality. $40 \%$ aqueous methylamine (Riedel-de Haën) and pure diethylamine (Fluka, puriss. p.a.) were used.

Solutions. The various solutions were prepared in volumetric flasks by weighing or pipet. ting from stock solutions. 2.5 M stock solutions of the alkylammonium nitrates were prepared by neutralizing, e.g., $1000 \mathrm{ml}$ of $5.00 \mathrm{M} \mathrm{HNO}$ with strong solutions of the amines, with 
stirring and cooling in ice, and then diluting to $2000 \mathrm{ml}$ with redistilled water. The working solutions $(2.00 \mathrm{M})$ of the alkylammonium nitrates were made from the stock solutions by 4/5-dilution in volumetric flasks, the diluent being water, aqueous amine or nitric acid as required. The equivalence of acid and base in the $2 \mathrm{M}$ alkylammonium nitrate solutions was determined by pH-measurements, and a correction was made, where necessary, for the self-dissociation of the protonated amine.

Acid-base constants of the amines. The concentration acid dissociation constants of the amines were determined by measuring the potential difference $\Delta E$ between $0.01 \mathrm{M}$ solutions of $\mathrm{HNO}_{3}$ and amine, respectively, in $2 \mathrm{M}$ alkylammonium nitrate medium by means of a glass electrode. The constant for the methyl-

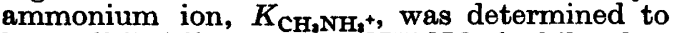
be $10^{-10.80} \pm 0.01$ in $2 \mathrm{M} \mathrm{CH}_{3} \mathrm{NH}_{3} \mathrm{NO}_{3},{ }^{8}$ whilst that for the diethylammonium ion, $K_{\left(\mathrm{C}_{2} \mathrm{H}_{8}\right)_{2} \mathrm{NH}_{3}+\text {, }}$ was found to be $10^{-11.12 \pm 0.01}$ in $2 \mathrm{M}\left(\mathrm{C}_{2} \mathrm{H}_{3}\right)_{2}$. $\mathrm{NH}_{2} \mathrm{NO}_{3}$.

Glass electrode measurements were performed in a jacketed vessel with thermostatted water flow. A selected Radiometer glass electrode (Type G 202 B) with the theoretical pH. dependence was used, and a specially constructed $1 \mathrm{M} \mathrm{KCl}$-calomel electrode was employed as reference. ${ }^{7}$ The potentiometer used was a Radiometer PHM 52 digital pH Meter, the $\mathrm{mV}$-scale being preferred to the direct reading $\mathrm{pH}$-scale.

Preparation of gerhardtite. To a mixture of $400 \mathrm{ml}$ of $10 \mathrm{M} \mathrm{NH}, \mathrm{NO}_{3}$ and $100 \mathrm{ml}$ of $0.5 \mathrm{M}$ $\mathrm{Cu}\left(\mathrm{NO}_{3}\right)_{2}$ in a 41 Erlenmeyer flask was added, with stirring, $50 \mathrm{ml}$ of $1.5 \mathrm{M}$ aqueous ammonia and $1300 \mathrm{ml}$ of distilled water, in that order. The solution was then placed on an electric hot plate with magnetic stirring and kept at about $60-70^{\circ} \mathrm{C}$. After some hours the solution became turbid and green crystals began to separate. The heating and stirring were continued for a day or more before the crystals were separated from the mother liquor. The crystals were washed several times with water, then with $96 \%$ ethanol and dried at $80^{\circ} \mathrm{C}$. The yield was about $5 \mathrm{~g}$.

Analysis of gerhardtite. Several portions were analyzed for copper by electrolysis in ammoniacal solutions, and for hydroxide by dis. solution in standardized $\mathrm{HCl}$ and back titration with $\mathrm{NaOH} .{ }^{5}$ The copper content found (52.8 to $53.2 \%$ ) was close to the theoretical value of $53.0 \%$, and the number of OH-groups per $\mathrm{Cu}$-atom was found to be $\mathbf{1 . 5 0}$ within a precision of about $1 \%$.

Solubility measurements were performed as follows: $2 \mathrm{M}$ alkylammonium nitrate solutions, containing known added amounts of $\mathrm{HNO}_{3}$ or of amine, were made up in $100 \mathrm{ml}$ volumetric flasks. After addition of about $0.3 \mathrm{~g}$ of gerhardtite the solutions were transferred into pyrex flasks with tight fitting stoppers and placed to rotate in a thermostatted water bath at $25^{\circ} \mathrm{C}$. Then, after a sufficient lapse of time, the saturated solutions were separated from undissolved gerhardtite by filtration through a fine porosity glass sinter filter. After measurement of $\mathrm{pH}=-\log \left[\mathrm{H}^{+}\right]$, the saturated solutions were kept in a thermostatted room at $25^{\circ} \mathrm{C}$, sometimes for a few days, before being

Table 1. Solubility data for gerhardtite in $2 \mathrm{M}$ methylammonium nitrate at $25^{\circ} \mathrm{C}$. $\mathrm{pH}=10.50-\mathrm{p}\left[\mathrm{CH}_{3} \mathrm{NH}_{2}\right]$.

\begin{tabular}{|c|c|c|c|c|c|c|c|c|c|}
\hline No. & $C^{\circ}{ }_{\text {HNO }}$ & $C^{\circ}{ }_{\text {am }}$ & $\mathbf{h}$ & $\mathrm{p} s_{\mathrm{Cu}}$ & $\mathrm{p}\left[\mathrm{Cu}^{2+}\right]$ & $\mathrm{p}$ [am] & $\mathrm{p} S$ & $\alpha_{\mathrm{CuOH}}$ & $\bar{n}$ \\
\hline $\mathbf{I}$ & $5.0 \times 10^{-3}$ & - & 439 & 2.45 & 2.37 & 5.35 & 10.40 & 0 & $\sim 0$ \\
\hline 2 & $9.9 \times 10^{-4}$ & - & 475 & 3.12 & 3.09 & 4.90 & 10.43 & 0 & 0.14 \\
\hline$\overline{3}$ & $7.4 \times 10^{-4}$ & - & 475 & 3.22 & 3.22 & 4.80 & 10.42 & 0 & 0.16 \\
\hline 4 & $2.3 \times 10^{-4}$ & - & 335 & 3.63 & 3.80 & 4.48 & 10.52 & 0.01 & 0.32 \\
\hline 5 & $1.0 \times 10^{-4}$ & - & 409 & 3.76 & 3.94 & 4.31 & 10.40 & 0.01 & 0.42 \\
\hline 6 & - & $2.2 \times 10^{-5}$ & 574 & 3.95 & 4.32 & 4.22 & 10.64 & 0.02 & 0.50 \\
\hline 7 & - & $4.8 \times 10^{-5}$ & 553 & 4.02 & 4.45 & 4.15 & 10.67 & 0.02 & 0.55 \\
\hline 8 & - & $1.2 \times 10^{-5}$ & 575 & 4.11 & 4.75 & 3.98 & 10.72 & 0.02 & 0.84 \\
\hline 9 & - & $2.5 \times 10^{-4}$ & 550 & 4.20 & 5.01 & 3.82 & 10.70 & 0.03 & 1.00 \\
\hline 10 & - & $5.2 \times 10^{-4}$ & 549 & 4.24 & 5.54 & 3.47 & 10.75 & 0.04 & 1.43 \\
\hline 11 & - & $1.1 \times 10^{-3}$ & 478 & 4.17 & 6.42 & 3.08 & 11.04 & 0.05 & 1.91 \\
\hline 12 & - & $2.1 \times 10^{-3}$ & 478 & 3.97 & 7.07 & 2.78 & 11.24 & 0.06 & 2.38 \\
\hline 13 & - & $1.1 \times 10^{-2}$ & 336 & 3.55 & 7.10 & 2.49 & 10.84 & 0.07 & 2.90 \\
\hline 14 & - & $1.4 \times 10^{-2}$ & 360 & 3.18 & 7.58 & 2.28 & 11.00 & 0.09 & 3.00 \\
\hline 15 & - & $3.5 \times 10^{-2}$ & $503^{a}$ & 2.57 & - & 1.86 & - & 0.14 & $\mathbf{3 . 3 0}$ \\
\hline $\begin{array}{l}16 \\
\text { Mean }\end{array}$ & - & $4.7 \times 10^{-2}$ & $502^{a}$ & 2.23 & - & 1.76 & $\overrightarrow{10.50}$ & 0.17 & - \\
\hline
\end{tabular}

a $C_{\mathrm{Cu}}^{\circ}=0.0104$, gerhardtite precipitated after mixing. 
Table 2. Solubility data for gerhardtite in $2 \mathrm{M}$ diethylammonium nitrate at $25^{\circ} \mathrm{C}$. $\mathrm{pH}=10.82-\mathrm{p}\left[\left(\mathrm{C}_{8} \mathrm{H}_{8}\right)_{2} \mathrm{NH}\right]$.

\begin{tabular}{|c|c|c|c|c|c|c|c|c|c|}
\hline No. & $C_{\text {HNOz }}^{\circ}$ & $C^{\circ}{ }_{\text {am }}$ & $\mathbf{h}$ & $\mathrm{p} s_{\mathrm{Cu}}$ & $\mathrm{p}\left[\mathrm{Cu}^{2+}\right]$ & $\mathrm{p}[\mathrm{am}]$ & $\mathrm{p} S$ & $\alpha_{\text {CuOH }}$ & $\bar{n}$ \\
\hline $\begin{array}{l}1 \\
2 \\
3 \\
4 a \\
4 b \\
5 \\
6 \mathrm{a} \\
6 \mathrm{~b} \\
7 \mathrm{a} \\
7 \mathrm{~b} \\
8 \mathrm{a} \\
8 \mathrm{~b} \\
\text { Mean }\end{array}$ & $\begin{array}{l}7.5 \times 10^{-8} \\
5.0 \times 10^{-3} \\
2.5 \times 10^{-8} \\
1.0 \times 10^{-3} \\
1.0 \times 10^{-8} \\
5.0 \times 10^{-4} \\
5.0 \times 10^{-6} \\
5.0 \times 10^{-6} \\
- \\
= \\
= \\
-\end{array}$ & $\begin{array}{l}\bar{z} \\
= \\
\overline{-} \\
\bar{z} \\
\overline{-} \\
2.4 \times 10^{-4} \\
2.4 \times 10^{-4} \\
4.8 \times 10^{-4} \\
4.8 \times 10^{-4}\end{array}$ & $\begin{array}{l}\mathbf{3 5 7} \\
\mathbf{3 5 6} \\
\mathbf{3 5 6} \\
\mathbf{3 1 2} \\
\mathbf{3 6 3} \\
\mathbf{3 6 2} \\
\mathbf{2 4 0} \\
\mathbf{4 0 8} \\
\mathbf{2 5 9} \\
\mathbf{3 3 3} \\
\mathbf{2 6 0} \\
\mathbf{3 3 4}\end{array}$ & $\begin{array}{l}2.31 \\
2.50 \\
2.79 \\
3.18 \\
3.17 \\
3.47 \\
4.19 \\
4.19 \\
4.94 \\
4.67 \\
5.14 \\
5.03\end{array}$ & $\begin{array}{l}2.30 \\
2.47 \\
2.79 \\
3.21 \\
3.21 \\
3.52 \\
4.48 \\
4.48 \\
- \\
4.88 \\
5.97 \\
5.63\end{array}$ & $\begin{array}{l}5.99 \\
5.89 \\
5.72 \\
5.43 \\
5.47 \\
5.29 \\
4.70 \\
4.73 \\
4.11 \\
4.38 \\
3.71 \\
3.89\end{array}$ & $\begin{array}{l}11.29 \\
11.31 \\
11.38 \\
11.36 \\
11.43 \\
11.46 \\
11.53 \\
11.59 \\
-11.45 \\
11.53 \\
11.46 \\
11.35\end{array}$ & $\begin{array}{l}0 \\
0 \\
0 \\
- \\
0 \\
0 \\
- \\
0.01 \\
0.04 \\
0.03 \\
0.06 \\
0.05\end{array}$ & $\begin{array}{l}0 \\
0 \\
0 \\
- \\
\sim 0 \\
\sim 0 \\
- \\
0.15 \\
0.70 \\
0.40 \\
1.10 \\
0.98\end{array}$ \\
\hline
\end{tabular}

analyzed for total and free copper(II).

The total copper(II) concentration $\left(C_{\mathrm{Cu}}\right)$ was determined by atomic absorption spectroscopy (Perkin-Elmer, Model 403), after dilution to $C_{\mathrm{Cu}} \simeq 10^{-6} \mathrm{M}$, by comparison with standard solutions of copper(II) in the same medium.

The free copper(II) ion concentration $\left[\mathrm{Cu}^{2+}\right]$ was tentatively measured with a Radiometer Cupric Selectrode $(\mathrm{F} 1112 \mathrm{Cu})$. The electrode gave tolerably good results when the copper(II) ion concentration was not too small.

\section{THE SOLUBILITY DATA}

A selection of the solubility data is presented in Tables 1 and 2. The quantities $C^{\circ}{ }_{\text {HNOs and }}$ $C_{\text {am }}^{\circ}$ in the tables denote the initial concentrations of nitric acid and amine, respectively. For the equilibrated solutions saturated with gerhardtite we have tabulated the exponent $\mathrm{p} s_{\mathrm{Cu}}$ of the solubility $\left[s_{\mathrm{Cu}}=C_{\mathrm{Cu}}\right.$ (sat.)], that of the free copper(II) ion, $p\left[\mathrm{Cu}^{2+}\right]$, and that of the free amine $p[\mathrm{am}]$, calculated from the relationship

$\mathrm{p}[\mathrm{am}]=\mathrm{p} K_{\mathrm{amH}^{+}}-\log 2-\mathrm{pH}$

or, in the case of the most basic solutions, measured directly relative to an amine standard in the medium used. The 4th column in the tables ("Hours") indicates the length of time in which the solutions have been shaken with gerhardtite. Establishment of the equilibrium was somewhat faster in the more acid solutions, but seems always to be reached after 300-400 h. However, it should be mentioned that in the case of saturated solutions close to the solubility minimum, with copper concentrations of the order $10^{-4}-10^{-5} \mathrm{M}$, the composition of the solutions moves somewhat towards lower $\mathrm{p}[\mathrm{am}]$, along the solubility curve, by prolonged equilibrium adjustment. This is probably due to reaction with traces of $\mathrm{CO}_{2}$ in the solutions (see, e.g., Nos. 7 and 8 in Table 2).

The solubility curves are shown in Fig. 1. All the experimental data are plotted in the figure and an explanation of the plotted points is given in the figure text. For comparison, Fig. 1 also gives the solubility curve for gerhardtite in $2 \mathrm{M} \mathrm{NH} \mathrm{NO}_{3}$, as determined by one of the present authors in $1931 .^{5}$ The great similarity of the shape of this curve to that found for gerhardtite in $2 \mathrm{M} \mathrm{CH} \mathrm{CH}_{8} \mathrm{NO}_{3}$ should be noted. In the $2 \mathrm{M}$ diethylammonium nitrate solutions, in which gerhardtite is even less soluble than in $2 \mathrm{M} \mathrm{CH}_{3} \mathrm{NH}_{3} \mathrm{NO}_{3}$, the solubility continues to decrease with increasing $\mathrm{pH}$ in the concentration range which could be studied. However, the solubility curve shows a decreasing slope and a minimum may be reached for $s_{\mathrm{Cu}} \sim 0.5 \times 10^{-5} \mathrm{M}$ at $\mathrm{p}$ [am] 3, but it should be mentioned that the solubility of the basic salt in this case shows little tendency to increase again, colourless solutions being formed throughout the whole range up to high amine concentration.

The curve for $2 \mathrm{M} \mathrm{NH}_{4} \mathrm{NO}_{3}$ continues, for $\mathrm{p}\left[\mathrm{NH}_{3}\right] \leqq 2.2$, into a solubility curve for the dark violet tetrammine copper(II) nitrate. For the $2 \mathrm{M} \mathrm{CH}_{3} \mathrm{NH}_{3} \mathrm{NO}_{3}$ medium the solubility

Acta Chem. Scand. A 30 (1976) No. 5 


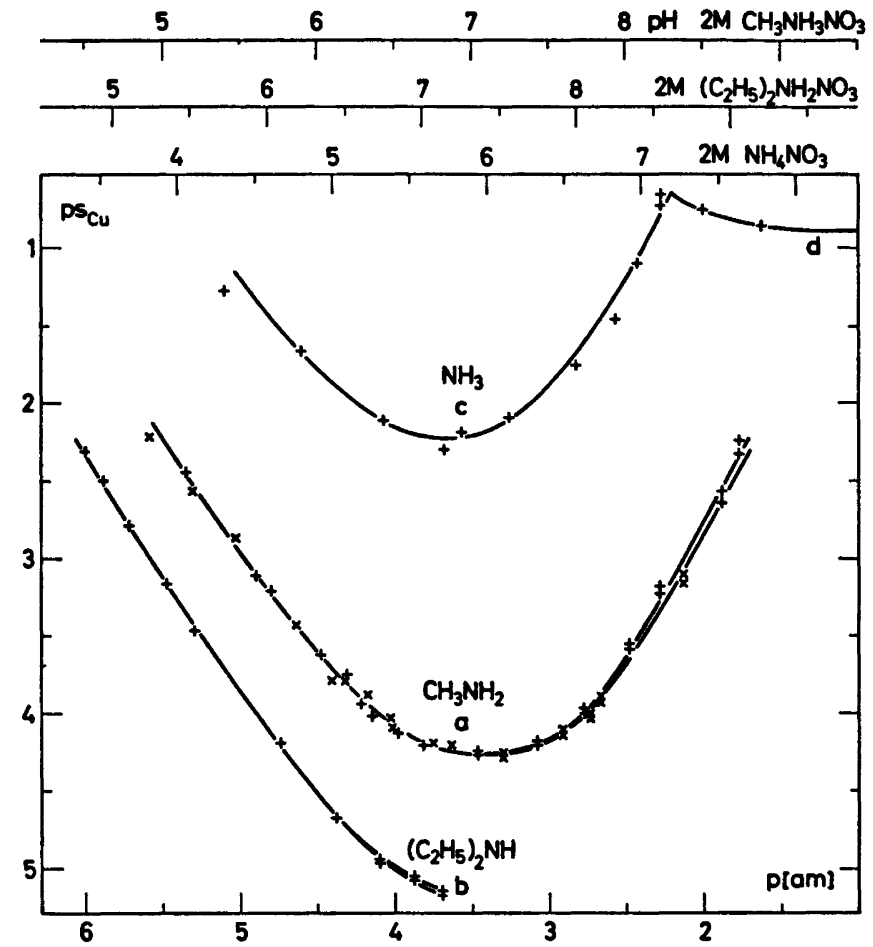

Fig. 1. The solubility curves for gerhardtite in $2 \mathrm{M}$ methylammonium nitrate (curve a) and in $2 \mathrm{M}$ diethylammonium nitrate (curve b) at $25^{\circ} \mathrm{C}$. All experimental results are shown. The points marked + correspond to the data tabulated in Tables 1 and 2. The data for the points marked $\times$ have not been tabulated, so as to reduce the size of the tables. In those cases where two points (either + or $x$ ) are placed vertically above each other, the upper point represents the experimentally deter. mined solubility and the lower point the solubility corrected for hydroxo complex formation.

For comparison purposes the previously determined solubility curves for gerhardtite (curve c) ${ }^{5}$ and tetrammine copper(II) nitrate (curved) ${ }^{8}$ in $2 \mathrm{M} \mathrm{NH}, \mathrm{NO}_{3}$ at $18^{\circ} \mathrm{C}$ are also shown in the figure.

curve for gerhardtite passes over at a definite (but undetermined) value of $\mathrm{p}\left[\mathrm{CH}_{3} \mathrm{NH}_{2}\right]$ into a curve for $\mathrm{Cu}(\mathrm{OH})_{2}$ This was noticed because the precipitate from a solution of the composi. tion $C^{\circ}{ }_{\mathrm{Cu}}=0.04 \mathrm{M}, C^{\circ} \mathrm{CH}_{3} \mathrm{NH}_{2}=0.14 \mathrm{M}$ turned, after some time, to black $\mathrm{CuO}$. It was further noticed that a very soluble dark violet salt, probably $\left[\mathrm{Cu}\left(\mathrm{CH}_{3} \mathrm{NH}_{2}\right)_{4}\left[\left(\mathrm{NO}_{3}\right)_{2}\right.\right.$, is the stable solid phase at high amine concentrations.

\section{THE SOLUBILITY PRODUCT OF GERHARDTITE}

In $2 \mathrm{M}$ alkylammonium nitrate solutions saturated with $\mathrm{Cu}(\mathrm{OH})_{1.5}\left(\mathrm{NO}_{3}\right)_{0.5}, S=\left[\mathrm{Cu}^{2+}\right]$. [am $]^{1.5}$ is a solubility constant. In Tables 1 and 2 are given values for $\mathrm{p} S=-\log S$. These values increase somewhat with increasing values for $\mathrm{p}\left[\mathrm{Cu}^{2+}\right]$, but this can be ascribed to the fact that the commercial $\mathrm{Cu}$ (II)-Selectrode used is not completely ideal in behaviour and shows deviations from Nernst's law. For this reason the values of $p S$ in the acid range where the copper(II) ions are mainly present as aqua ions are assumed to be the most reliable, and the average values for $\mathrm{p} S$ given in Tables 1 and 2 are estimated in accordance with this assumption.

The exponent of the solubility product for gerhardtite: $K_{\mathrm{s}}=\left[\mathrm{Cu}^{2+}\right]\left[\mathrm{OH}^{-}\right]^{1.5}\left[\mathrm{NO}_{3}^{-}\right]^{0.5}$ in $2 \mathrm{M}$ alkylammonium nitrate solutions can be ex. pressed as follows:

$$
\mathrm{p} K_{\mathrm{s}}=\mathrm{p} S+1.5 \log \left(\frac{2 \times K_{\mathrm{amH}}}{K_{\mathrm{w}}}\right)-0.5 \log 2
$$

Acta Chem. Scand. A 30 (1976) No. 5 
Using the values found for $\mathrm{p} K_{\mathrm{amH}^{+}}(10.80$ for $\mathrm{CH}_{3} \mathrm{NH}_{3}+$, and 11.12 for $\left.\left(\mathrm{C}_{3} \mathrm{H}_{3}\right)_{2} \mathrm{NH}_{2}{ }^{+}\right)$ and Harned's value for the ionic product of water in $2 \mathrm{M} \mathrm{KCl}$ at $25^{\circ} \mathrm{C}\left(\mathrm{p} K_{\mathrm{w}}=14.10\right), 9$ $\mathrm{p} K_{\mathrm{S}}$ is calculated to be 15.75 in $2 \mathrm{M}$ $\mathrm{CH}_{3} \mathrm{NH}_{3} \mathrm{NO}_{3}$, and 16.12 in $2 \mathrm{M}\left(\mathrm{C}_{2} \mathrm{H}_{5}\right)_{2} \mathrm{NH}_{2} \mathrm{NO}_{3}$ at $25^{\circ} \mathrm{C}$.

A value of $\mathrm{p} S=8.77$ for gerhardtite in $2 \mathrm{M}$ $\mathrm{NH}_{4} \mathrm{NO}_{3}$ at $18^{\circ} \mathrm{C}$ has previously been found. ${ }^{\mathrm{s}}$ In this medium $\mathrm{p} K_{\mathrm{NH}_{+}+}=9.40$ at $18^{\circ} \mathrm{C}^{10}$ and using Harned's value of $\mathrm{p} K_{\mathrm{w}}=14.34$ in $2 \mathrm{M}$ $\mathrm{KCl}$ at $18^{\circ} \mathrm{C}, 9^{\circ}$ one obtains $\mathrm{p} K_{\mathrm{s}}=16.03$, to be compared with the values for $\mathrm{p} K_{\mathrm{s}}$ in the other media at $25^{\circ} \mathrm{C}$.

\section{THE INFLUENCE OF HYDROXO COMPLEX FORMATION}

Methylamine and diethylamine are considerably stronger bases than ammonia and the possibility of hydroxo complex formation influencing the copper(II)-amine formation in the alkylammonium salt solutions must therefore be taken into account. The main products of the hydrolysis of copper(II) ions in dilute aqueous solutions are $\mathrm{CuOH}^{+}$and $\mathrm{Cu}_{2}$ $(\mathrm{OH})_{2}{ }^{2+} .{ }^{11-13}$ Denoting the hydrolysis constants as in "Tables of Stability Constants"," the concentrations of these species are given by the expressions:

$[\mathrm{CuOH}+]=* K_{1}\left[\mathrm{Cu}^{2+}\right] /\left[\mathrm{H}^{+}\right]$

$\left[\mathrm{Cu}_{2}(\mathrm{OH})_{2}{ }^{2+}\right]={ }^{*} \beta_{2,2}\left[\mathrm{Cu}^{2+}\right]^{2} /[\mathrm{H}+]^{2}$

and the fraction of copper(II) bound as hydroxo complex by the expression

$\alpha_{\mathrm{OH}}=\frac{* K_{1}\left[\mathrm{H}^{+}\right]+0.5^{*} \beta_{2,2}\left[\mathrm{Cu}^{2+}\right]}{\left[\mathrm{H}^{+}\right]^{2}+{ }^{*} K_{1}\left[\mathrm{H}^{+}\right]+0.5^{*} \beta_{2,2}\left[\mathrm{Cu}^{2+}\right]}$

From the data of Pedersen 11 and Perrin ${ }^{13}$ the hydrolysis constants in $2 \mathrm{M}$ nitrate solutions at $25^{\circ} \mathrm{C}$ can be estimated to be ${ }^{*} K_{1} \cong 10^{-8}$ and ${ }^{*} \beta_{2,2}=2 \times 10^{-11}$. The values of the hydrolysis constants for the aqua ammine systems are unknown, although ${ }^{*} K_{1}$ for $\mathrm{Cu}\left(\mathrm{NH}_{3}\right)_{3} \mathrm{H}_{2} \mathrm{O}^{2+}$ can be estimated from data in the literature..$^{15,10}$ Reeves and Bragg ${ }^{15}$ have titrated dilute solutions of $\mathrm{Cu}\left(\mathrm{NH}_{3}\right)_{4}{ }^{2+}$ in $1 \mathrm{M}$ aqueous ammonia with $\mathrm{NaOH}$ and found for the uptake of the first $\mathrm{OH}^{-}$:

$$
K_{\mathrm{OH}}=\frac{\left[\mathrm{Cu}\left(\mathrm{NH}_{3}\right)_{3} \mathrm{OH}+\right]\left[\mathrm{NH}_{3}\right]}{\left[\mathrm{Cu}\left(\mathrm{NH}_{3}\right)_{4}{ }^{2+}\right]\left[\mathrm{OH}^{-}\right]}=10^{2.40}
$$

Acta Chem. Scand. A 30 (1976) No. 5
* $K_{1}$, the acid dissociation constant for $\mathrm{Cu}\left(\mathrm{NH}_{3}\right)_{3} \mathrm{OH}_{2}^{2+}$, is related to $K_{\mathrm{OH}}$ by the expression:

${ }^{*} K_{1}=K_{\mathrm{OH}} \times K_{4} \times K_{\mathrm{w}}=10^{2.40} \times 10^{2.05} \times 10^{-14.10}=$ $10^{-9.65}$

In this expression $K_{t}=10^{2.05} 1 \mathrm{~mol}^{-1}$ is the stability constant for binding the fourth ammonia, and $K_{\mathrm{w}}=10^{-14.10}$ is the ionic product of water. The values of $* K_{1}$ for the aliphatic amine complexes cannot be very different from those for the ammonia complexes and are perhaps somewhat lower. We have therefore corrected for the hydroxo complex formation by assuming that $* K_{1}$ increases smoothly from $10^{-9.5}$ for $\mathrm{Cu} \mathrm{am}_{3} \mathrm{H}_{2} \mathrm{O}^{2+}$ to $10^{-8}$ for $\mathrm{Cu} \mathrm{aq}{ }^{2+}$. The value for ${ }^{*} \beta_{2,2}=2 \times 10^{-11}$ has been used without correction since the corresponding hydrolysis reaction only contributes to a slight extent to the hydrolysis at the low copper concentrations involved in the solubility measurements. The estimated values for $\alpha_{\mathrm{OH}}$ are presented in Tables 1 and 2. In Table $1,{ }^{*} K_{1}$ was taken to be $10^{-8}$ for Nos. $1-8,0.5 \times 10^{-8}$ for Nos. $9-10,2 \times 10^{-9}$ for No. $11,10^{-9}$ for No. $12,0.5 \times 10^{-\circ}$ for Nos. $13-14$, and $0.3 \times 10^{-\circ}$ for Nos. 15-16, whereas in Table 2 a value of $10^{-8}$ was used for Nos. $1-6$, and $0.5 \times 10^{-8}$ for Nos. 6-7. It can be seen that the correction for hydroxo complex formation is really sig. nificant - more than $10 \%$ - only at relatively high amine concentrations $(\mathrm{pH} \gtrsim 9)$.

\section{ESTIMATION OF THE STABILITY CONSTANTS}

A closer examination of the solubility data shows that the best way to estimate the stability constants is by means of the formation curve $\bar{n} v s . p[a m]$. Values of $\bar{n}$ can be obtained directly from the slope of the solubility curve at any $\mathrm{p}[\mathrm{am}]$ by means of the formula:

$$
\frac{d \log s_{\mathrm{Cu}}}{\mathrm{d} \log [\mathrm{am}]}=\frac{\mathrm{d} \mathrm{p} s_{\mathrm{cu}}}{\mathrm{dp}[\mathrm{am}]}=n-1.5
$$

This formula can be derived as follows: Introducing $\alpha_{0}=\left[\mathrm{Cu}^{2+}\right] / s_{\mathrm{Cu}}$ into the simple Bodländer formula, ${ }^{10}$ one obtains:

$$
\frac{d \log \alpha_{0}}{d \log [\mathrm{am}]}=\frac{\mathrm{d} \log \left[\mathrm{Cu}^{2+}\right]}{\mathrm{d} \log [\mathrm{am}]}-\frac{\mathrm{d} \log 8_{\mathrm{Cu}}}{\mathrm{d} \log [\mathrm{am}]}=-\bar{n}
$$




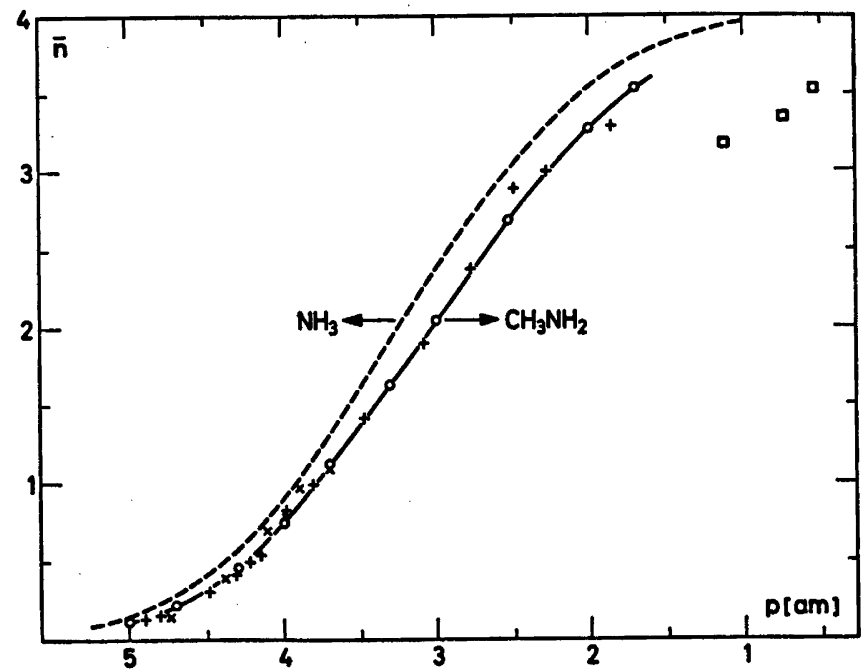

Fig. 2. The formation curve for the copper(II) methylamine system in $2 \mathrm{M} \mathrm{CH}_{3} \mathrm{NH}_{3} \mathrm{NO}_{3}$ at $25^{\circ} \mathrm{C}$. The + points represent the experimental values from Table 1 , and the $O$ points represent values calculated using the computed stability constants given in Table 3. The $\square$ points are uncorrected values obtained from the relationship $\bar{n}=\left(C_{\mathrm{am}}-[\mathrm{am}]\right) / C_{\mathrm{Cu}}$ by means of glass electrode measurements on $0.05-0.10 \mathrm{M} \mathrm{Cu}\left(\mathrm{NO}_{3}\right)_{2}, 2 \mathrm{M} \mathrm{CH} \mathrm{NH}_{3} \mathrm{NO}_{3}$ solutions with sufficiently high concentrations of $\mathrm{CH}_{3} \mathrm{NH}_{2}$ to prevent basic precipitation. The $\times$ points close to the methylamine curve represent the data for the diethylamine system from Table 2. The dashed formation curve in the figure is the curve for the copper(II) ammonia system under the same conditions $\left(2 \mathrm{M} \mathrm{NH}_{4} \mathrm{NO}_{3}\right.$ at $25^{\circ} \mathrm{C}$ )..$^{10}$

From the expression for the saturation constant $S=\left[\mathrm{Cu}^{2}+\right][\mathrm{am}]^{1.5}$, one obtains $\mathrm{d} \log$ $\left[\mathrm{Cu}^{2+}\right]=-1.5 \mathrm{~d} \log [\mathrm{am}]$, which inserted in the Bodländer formula gives the required expression.

The derived expression shows directly that the solubility curve has a minimum for $\bar{n}=1.5$. However, strictly speaking the formula is only valid for a pure aqua-ammine formation. In order to use it correctly it is necessary first to correct the solubility for hydroxo complex formation. In our case this is done simply by multiplying $s_{\mathrm{Cu}}$ by $\left(1-\alpha_{\mathrm{OH}}\right)$. In Fig. 1 the corrected values for $\mathrm{ps}_{\mathrm{Cu}}$ are plotted vertically below the experimental solubilities, and it can be seen that the correction is generally small and for methylamine results in only a small decrease in the slope of the ascending branch of the solubility curve for $\mathrm{pH}>7$.

Values for the ligand number $\bar{n}$ derived from the slopes of the corrected solubility curves are tabulated in Tables 1 and 2. The formation curve for the copper(II) methylamine system, drawn from the data given in Table 1 (points marked + ), is shown in Fig. 2 .
The data for the diethylamine system, taken from Table 2 (points marked $x$ ), are also shown. These points are seen to lie rather close to the methylamine complex formation curve. It is also notable that the stabilities of the aliphatic amine complexes are only slightly smaller than those of the ammonia complexes; this can be seen by comparison with the dotted curve in the figure, which represents the formation curve for the copper(II)-ammonia system under the same conditions ( $2 \mathrm{M} \mathrm{NH} \mathrm{NO}_{3}$ at $\left.25^{\circ} \mathrm{C}\right) . .^{10}$

The stability constants for the methylamine system have been computed from the experimental data and the values are given in Table 3. The $O$ points in Fig. 2 are calculated by means of these constants, and it can be seen how well the curve drawn through these points agrees with the experimental + points. The limited data given for the diethylamine system (the $x$ points in the figure) show that the first stability constants for this system must have about the same values as those for the methylamine system, but the uncertainty in the measurements is too great to justify giving values for these constants.

Acta Chem. Scand. A 30 (1976) No. 5 
Table 3. Comparison of the consecutive stability constants for some metal-ion methylamine systems with those for the analogous ammonia systems under similar conditions at $25^{\circ} \mathrm{C}$.

\begin{tabular}{llllllc}
\hline System & Medium & $\log K_{1}$ & $\log K_{2}$ & $\log K_{3}$ & $\log K_{6}$ & Ref. \\
\hline $\mathrm{Cu}(\mathrm{II}), \mathrm{CH}_{3} \mathrm{NH}_{2}$ & $2 \mathrm{M} \mathrm{CH}_{3} \mathrm{NH}_{3} \mathrm{NO}_{3}$ & 4.11 & 3.40 & 2.70 & 1.87 & This paper \\
$\mathrm{Cu}(\mathrm{II}), \mathrm{NH}_{3}$ & $2 \mathrm{M} \mathrm{NH} \mathrm{NO}_{3}$ & 4.22 & 3.57 & 2.95 & 2.20 & 10 \\
$\mathrm{Cd}(\mathrm{II}), \mathrm{CH}_{3} \mathrm{NH}_{2}$ & $2 \mathrm{M} \mathrm{CH}_{3} \mathrm{NH}_{3} \mathrm{NO}_{3}$ & 2.75 & 2.06 & 1.13 & 0.61 & 4 \\
$\mathrm{Cd}(\mathrm{II}), \mathrm{NH}_{3}$ & $2 \mathrm{M} \mathrm{NH} \mathrm{NO}_{3}$ & 2.69 & 2.14 & 1.48 & 0.97 & 10 \\
$\mathrm{Hg}(\mathrm{II}), \mathrm{CH}_{3} \mathrm{NH}_{2}$ & $0.5 \mathrm{M} \mathrm{CH}_{3} \mathrm{NH}_{3} \mathrm{NO}_{3}$ & 8.7 & 9.2 & 0.3 & 0.3 & 3 \\
$\mathrm{Hg}(\mathrm{II}), \mathrm{NH}_{3}$ & $2 \mathrm{M} \mathrm{NH} \mathrm{NO}_{3}$ & 8.8 & 8.7 & 1.0 & 0.8 & 10 \\
$\mathrm{Ag}(\mathrm{I}), \mathrm{CH}_{3} \mathrm{NH}_{2}$ & $0.5 \mathrm{M} \mathrm{CH}_{3} \mathrm{NH}_{8} \mathrm{NO}_{3}$ & 3.15 & 3.53 & & & 1,14 \\
$\mathrm{Ag}(\mathrm{I}), \mathrm{NH}_{3}$ & $0.5 \mathrm{M} \mathrm{NH} \mathrm{NO}_{3}$ & 3.30 & 3.93 & & & 10 \\
\hline
\end{tabular}

\section{DISCUSSION OF RESULTS AND COMPARISON WITH LITERATURE DATA}

In Table 3 our stability constants for the copper(II)-methylamine system are compared with those for some other metal-ion methylamine systems, as well as with the constants for the corresponding metal-ion ammonia systems under similar conditions. The constants given for the mercury(II) and silver(I) systems are all taken from earlier work by one of the present authors. ${ }^{1,3}, 10$ The constants for the cadmium(II) methylamine system are taken from a paper of Spike and Parry.4 The basic precipitates have a rather high solubility with the latter system, and it is the only methylamine system with the characteristic coordination number higher than two for which stability constants have hitherto been obtained.

The data collected in Table 3 show that am. monia and methylamine have nearly the same affinity towards complex formation. The greater steric bulk of methylamine has a slight in. fluence only on the uptake of the last amine molecules. Thus, the values for $K_{1}$ in the copper(II)- and cadmium(II)-methylamine systems are almost the same as in the ammonia systems, whilst the values of $K_{4}$ decrease to about half of those in the latter. In the case of diethylamine only the first part of the solubil. ity curve could be determined, but it is note. worthy that the much larger bulk of this amine does not seem to have any appreciable influence on the uptake of the first amine molecule (see the $\times$ points in Fig. 2). However, a steric effect must be expected for the uptake of sub. sequent diethylamine molecules. By extrapolation to the supposed minimum in the solubility curve (see Fig. 1) it can be estimated that $\bar{n}=1.5$ for $\mathrm{p}[\mathrm{am}] \sim 3$, which is consistent with a considerable steric effect ( $c f$. the formation curves in Fig. 2). However, the influence of hydroxo complex formation and possibly precipitation of copper(II) hydroxide is so pronounced in this case that a detailed study is difficult.

Bjerrum and Lamm ${ }^{6}$ have previously esti. mated that $K_{4}$ for the copper(II)-methylamine system should be $20-25$ times less than for the ammonia system. This result was obtained from the relationship: $\bar{n}=\left(C_{\mathrm{am}}-[\mathrm{am}]\right) /$ $C_{\text {Cu}}$, using glass electrode measurements on solutions stabilized with relatively high concentrations of copper(II) and methylamine relative to the methylammonium nitrate in the medium. However, such measurements only give approximate values for $\bar{n}$ which have to be corrected for salt effects., ${ }^{3,10}$ If the activity coefficient of methylamine increases with concentration, as is the case for ammonia, one should expect to obtain values of $\vec{n}$ which are too low. We have made a few measurements on solutions with $C_{\mathrm{Cu}} \sim 0.05-0.10 \mathrm{M}$ and $\mathrm{C}_{\mathrm{CH}_{2} \mathrm{NH}_{2}} \sim 0.2-0.5 \mathrm{M}$ in $2 \mathrm{M} \mathrm{CH}_{8} \mathrm{NH}_{3} \mathrm{NO}_{3}$ and confirmed that such measurements result in values for $\bar{n}$ which are too low (see the points in Fig. 2).

Finally we wish to draw attention to an error in "Tables of Stability Constants". ${ }^{\text {" I }}$ In Supple. ment No. 1 are erroneously given stability constants for diethylamine complexes of $\mathrm{Cd}(\mathrm{II})$, $\mathrm{Co}(\mathrm{II}), \mathrm{Ni}(\mathrm{II})$, and $\mathrm{Zn}(\mathrm{II})$. The authors con-

Acta Chem. Scand. A 30 (1976) No. 5 
cerned ${ }^{17,18}$ have not understood that when one titrates with diethylamine in $2 \mathrm{M} \mathrm{NH} \mathrm{NO}_{3}$, it is the constants for the ammonia complexes and not the diethylamine complexes which are obtained.

Acknowledgement. The authors thank Dr. Martin Hancock for correcting the English manuscript.

\section{REFERENCES}

1. Bjerrum, J. Chem. Revs. 46 (1950) 381.

2. Bjerrum, J. and Refn, S. Suom. Kemistil. $B 29$ (1956) 68.

3. Bjerrum, J. Acta Chem. Scand. 26 (1972) 2734.

4. Spike, C. G. and Parry, R. W. J. Am. Chem. Soc. 75 (1953) 2726.

5. Bjerrum, J. K. Dan. Vidensk. Selsk., Mat.Fys. Medd. 11 (1931) No. 5.

6. Bjerrum, J. and Lamm, C. G. Acta Chem. Scand. 4 (1950) 997.

7. Lewis, G. N., Brighton, T. B. and Sebas. tian, R. L. J. Am. Chem. Soc. 39 (1917) 2245.

8. Bjorrum, J. K. Dan. Vidensk. Selsk., Mat.Fys. Medd. 11 (1932) No. 10.

9. Harned, H. S. and Hamer, W. I. J. Am. Chem. Soc. 55 (1933) 2194.

10. Bjerrum, J. Metal ammine formation in aqueous solution, P. Haase and Son, Copenhagen 1941; reprinted 1957.

11. Pedersen, K. J. K. Dan. Vidensk. Selsk., Mat.-Fys. Medd. 20 (1943) No. 7.

12. Berecki-Biedermann, C. Ark. Kemi 9 (1956) 175.

13. Perrin, D. D. J. Chem. Soc. (1960) 3189.

14. Sillén, L. G. and Martell, A. E. Stability Constants, Chem. Soc. Spec. Publ. 17 (1964), and Suppl. 25 (1970).

15. Reeves, R. E. and Bragg, P. J. Am. Chem. Soc. 84 (1962) 2491.

16. Fisher, J. F. and Hall, J. L. Anal. Chem. 39 (1967) 1550.

17. Popa, G. and Magearu, V. Rev. Roum. Chim. 12 (1967) 1107.

18. Popa, G., Magearu, V. and Luca, C. $J$. Electroanal. Chem. 17 (1968) 335.

Received December 19, 1975. 